\title{
Genetics Research
}

\author{
INSTRUCTIONS FOR CONTRIBUTORS
}

Genetics Research publishes papers on all aspects of the genetics of complex traits. Excellent papers in other areas of genetics are also welcome. Specifically, the journal publishes empirical and theoretical studies on evolutionary and population genetics, quantitative and statistical genetics, genomics and systems genetics, and molecular and developmental genetics. On the empirical side papers reporting studies that have broad implications using a range of organisms, from well-established genetic model organisms (flies, $C$. elegans, mice, yeast, Arabidopsis); agricultural species (cows, pigs, sheep, chickens, rice, maize, wheat) to humans are encouraged. In addition to research articles the journal welcomes reviews that deal with any field within its scope.

Contributions are welcomed from scientists of all nationalities but must be written in English. Submission of a paper will be taken to imply that it is unpublished and is not being considered for publication elsewhere. Papers should be as concise as clarity permits, and illustrations should be restricted to the minimum needed. Short Papers are designed for concisely written reports of work for which rapid publication is considered desirable. Such papers will normally be published within three months of receipt in acceptable form. They should not exceed 4 pages of print in length, and should include a summary.

Submissions These should be made via the journal's online submission systemathttp://www.editorialmanager.com/genetics. They should be typed in font size 12 and double-spaced.

The title should ordinarily identify the organism. The address of the laboratory at which the work was carried out will be printed with the authors' names at the head of the paper, and changes of address may be added in footnotes. A footnote to the title page should also give the name and address to whom reprint requests may be made. Sources of financial support should be included with other acknowledgements at the end of the text.The title page of the typescript should include a short title for running headlines (limited to 50 letters and spaces), and the name and address of the author (or his proxy) to whom the proofs are to be sent, under the heading: Proofs to be sent to . . . Main headings should be typed in capitals and (except summary and references) numbered consecutively. Subheadings should be typed in lower case, and italicized except for those words and symbols which would be italicized in the text. Subheadings should be numbered (i), (ii), etc., within each main heading. There are no page charges for this journal.

Summary The summary will be printed at the beginning of the paper. It should give a concise abstract of the significant content and conclusions of the paper, in a form suitable for abstracting journals to use, and should not exceed 250 words.

Illustrations Colour illustrations are now published free of charge for this journal - for both the online and printed versions. All illustrations, including photographs, diagrams, graphs etc. are to be labelled consecutively Figure $1,2 \ldots$ according to their relative positions in the text. Each figure should have a legend to be printed underneath it. Photographs should also be supplied by post as unmounted glossy prints, with a sketch or separate set to show the arrangement required when several photographs are to form one figure. The names of the authors and the orientation of the figure should be indicated on the back of each photograph. Diagrams should be about twice the size of the printed figure, but not larger than $305 \times 203 \mathrm{~mm}(12 \times 8$ inches $)$, unless exceptionally complicated, and the thickness of lines and size of points should be determined accordingly.

Tables Each table should be typed on a separate sheet of paper and its approximate position in the text indicated on the typescript. Each should be numbered and carry an appropriate title. The table should be designed, whenever possible, to be printed in the normal orientation of the text. The data should be grouped so as to make the use of rules unnecessary, for they will only be included at the Editor's discretion. Table footnotes should ordinarily employ the symbols $*, \dagger, \ddagger, \S, \|, \boldsymbol{\mathscr { I }}, * *$, etc., in that order.

Symbols Gene and mathematical symbols should generally be printed in italics, matrices in boldface. Note that ' + ' as the symbol for a wild-type allele should not be italicized.

Nomenclature Wherever possible, standardized nomenclature should be employed. The author should refer to the following publications for guidance: Novick et al. (Bacteriological Reviews 40, 168-189) for plasmids; O'Brien (Ed.), Genetic Maps 6, Cold Spring Harbor 1993, for information on most species and recent gene lists.

References should follow the normal usage in the journal. In the list of references at the end of the paper, both titles of articles and names of periodicals should be written out in full.

Distribution of Reagents and Deposition of Sequences Manuscripts will only be accepted for publication in Genetics Research on the understanding that protein and nucleic acid sequence data is deposited in a suitable public database, and polymorphism data is deposited in HGBASE. The corresponding accession numbers must be included in the paper. Authors must also be willing to distribute freely, for academic research, any new strains, clones or antibodies that they describe.

Proofs Authors will be advised by email when to download their proofs from the Cambridge University Press website. These proofs, after correction, should be returned to the Executive Editor. Excessive alterations, other than corrections of printers' errors, may be disallowed or charged to the author. Corrections should be made using the symbols in British Standard 1219: 1958, or its shortened version B.S. 1219C: 1958

Offprints Authors will be provided with a free pdf of their article and offprints may be ordered in using form sent out with proofs, provided this is returned within fourteen days of receipt.

This journal issue has been printed on FSC-certified paper and cover board. FSC is an independent, non-governmental, not-for-profit organization established to promote the responsible management of the world's forests. Please see www.fsc.org for information.

\section{Cambridge University Press}

The Edinburgh Building, Cambridge CB2 8RU, United Kingdom

32 Avenue of the Americas, New York, NY 10013-2473, USA

477 Williamstown Road, Port Melbourne, VIC 3207, Australia

C/ Orense, 4, Planta 1328020 Madrid, Spain

Lower Ground Floor, Nautica Building, The Water Club, Beach Road, Granger Bay, 8005, Cape Town, South Africa 


\section{GENETICS RESEARCH}

\section{CONTENTS}

\section{RESEARCH PAPERS}

The copia retrotransposon and horizontal transfer in Drosophila willistoni

P. M. Rubin, E. L. S. Loreto, C. M. A. Carareto \& V. L. S. Valente

Long-term evolution of the roo transposable element copy number in mutation accumulation lines of Drosophila melanogaster

Julia Díaz-González, J. Fernando Vázquez, Jesús Albornoz \& Ana Domínguez

Prediction of body mass index in mice using dense molecular markers and a regularized neural network Hayrettin Okut, Daniel Gianola, Guilherme J. M. Rosa \& Kent A. Weigel
The distribution of SNP marker effects for faecal worm egg count in sheep, and the feasibility of using these markers to predict genetic merit for resistance to worm infections

Kathryn E. Kemper, David L. Emery, Stephen C. Bishop, Hutton Oddy, Benjamin J. Hayes, Sonja Dominik, John M. Henshall \& Michael E. Goddard

Mapping Mendelian traits in asexual progeny using changes in marker allele frequency

Sayanthan Logeswaran \& Nick H. Barton

Mating system and the critical migration rate for swamping selection 